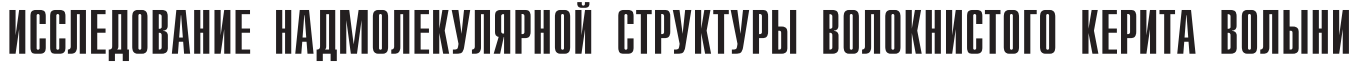

\author{
Е. А. Голубев ${ }^{1}$, О. В. Мартиросян ${ }^{2}$ \\ ${ }^{1}$ Институт геологии Коми НЦ УрО РАН, Сыктывкар; golubev@geo.komisc.ru \\ ${ }^{2}$ ВИМС, Москва
}

Приведены результаты изучения волынского волокнистого керита методами атомно-силовой и растровой электронной микроскопии, ИК-спектроскопии, термического анализа. Описана надмолекулярная структура керита, представленная прежде всего наноразмерными волокнами и в меньшей степени глобулами. Результаты ИК-спектроскопии и термического анализа показывают, что по своей химической структуре волынский керит, ранее причислявшийся к классу высших окисленных керитов, больше соответствует низшим окисленным керитам. Это исследование посвящено памяти академика Н. П. Юшкина, который в последние годы своей жизни уделял много внимания этому уникальному природному битуму, рассматривая его в качестве одного из фундаментальных блоков при создании своей теории углеводородных веществ как предшественников биологических организмов.

Ключевые слова: волынский керит, надмолекулярная структура, атомно-силовая микроскопия, ИК-спектроскопия, термический анализ.

\section{STUDY OF SUPERMOLECULAR STRUCTURE OF FIBROUS KERITE FROM VULYN}

\author{
Ye. A. Golubev ${ }^{1}$, O. V. Martirosyan ${ }^{2}$ \\ ${ }^{1}$ Institute of Geology Komi SC UB RAS, Syktyvkar \\ ${ }^{2}$ VIMS, Moscow
}

We present results of the study of Volyn fibrous kerite by the atomic force and scanning electron microscopy, infrared spectroscopy, thermal analysis. The supermolecular structure of kerite, consisting of nano-sized fibers and globules, is described. The results of IR spectroscopy and thermal analysis show that Volyn kerite previously ranked among the higher oxidized kerite group, chemically corresponds to the lower oxidized kerite. This research is devoted to the memory of Academician N. P. Yushkin who in his last years devoted much attention to this unique natural bitumen. He considered it as one of the fundamental building blocks to create his theory of hydrocarbons crystals as protoorganisms and biological systems predecessors.

Keywords: Volyn kerite, supermolecular structure, atomic force microscopy, infrared spectroscopy, thermal analysis.

\section{Введение}

Одним из необычных по форме проявлений среди природных твердых битумов является волокнистый керит из пегматитов Волыни, обнаруженный геологами ПГО «Западкварцсамоцвет» в 1981 году на глубине 80 м в одном из занорышей камерных пегматитов Волыни (Украина) вместе с кристаллами и обломками кристаллов кварца, топаза, полевого шпата. Вещество, впервые описанное специалистами ВИМСа и ИГЕМа в совместной работе [1], а затем детально охарактеризованное Н. П. Юшкиным $[10,11,16]$, представляет собой спутанно-волокнистую (войлокообразную) массу, состояшую из агрегатов мельчайших (диаметром от единиц до десятков микрон) волокон. Необычность морфологии, делающая волынский керит уникальным представителем минералоидов, имеющим собственную форму индивидов, наряду с возрастающим в плане индустриального применения интересом к углеродным волокнам стимулировали изучение волокнистого керита с генетической и структурной точек зрения. Согласно данным химических исследований, он был отнесен к высшим окисленным керитам (оксикеритам) [1]. Результаты структурных исследований, проведенных методами рентгеновской дифрактометрии и электронографии, не выявляют кристаллической структуры и свидетельствуют о том, что волынский керит является рентгеноаморфным [1]. Однако есть данные, указывающие на наличие упорядоченных доменов размерами до 0.5 нм, структура которых близка графитовой [11]. В работах $[8,11]$ сообщалось, что не удалось обнаружить не только морфоструктуру на поверхности волокон, но и признаки внутреннего надмолекулярного строения, был отмечен только характерный раковистый излом и гладкость поверхности, за исключением отдельных микродефектов. Позднее электронно-микроскопические снимки в просвечивающей геометрии $[16,17]$ позволили выявить неоднородности внутреннего строения волокон, показывая наличие молекулярных ансамблей кластеров в виде атомных цепочек, формирующих кольца и подковы средним размером 5 нм, иногда образующих глобулы размерами до 1 м и имеющих поры 10-20 нм.

В составе керита были определены различные насыщенные, разветвленные и гидроксильные жирные кислоты [14], однако не были обнаружены некоторые типичные для нефтяных битумов элементы, такие как ванадий и никель [17].

Характерные формы волокон, а также особенности химического состава (в частности, наличие некоторых аминокислот) позволили Н. П. Юшкину рассматривать волокна этого керита в качестве предбиологических моделей организмов [16, 17]. С генетической точки зрения волокна керита рассматриваются как продукт роста из газа, преимушественно метана, катализируемого металлическими частичками по механизму пар-жидкостькристалл $[2,5,15,17]$, а с морфологической - как фиброкристаллы $[11,12,16]$.

Среди всех аспектов представлений о волынском керите меньшее внимание уделялось надмолекулярной 
структуре волокон, хотя она является характерной для многих природных твердых битумов [8, 13]. В данной работе изложены результаты изучения строения волокон керита на субмикронном уровне с помощью атомно-силовой микроскопии. Дополнительно с помощью термического анализа, ИК-спектроскопии, растровой электронной микроскопии, а также при изучении структурных изменений волокнистого керита в процессе температурного воздействия $\left(500{ }^{\circ} \mathrm{C}\right.$ в течение 10 часов) получены новые характеристики этого уникального природного битума

\section{Материал и методика исследования}

Анализировались образцы волокнистого керита из коллекции Н. П. Юшкина. Были исследованы волокна различного диаметра, от 1 до 35 мкм (рис. 1).

Для проведения ИК-спектроскопии образцы тщательно измельчали в агатовой ступке до порошкообразного состояния и анализировали на ИК-спектрометре Avatar 360 FT-IR фирмы Nicolet Instruments (США) с использованием приставки МНПВО Nicolet Smart MIRacle фирмы Pike Technologies (США) в диапазоне волновых чисел 4000-600 $\mathrm{cm}^{-1}$ с разрешением $4 \mathrm{~cm}^{-1}$. Для снятия спектров образцы прикладывали к кристаллу ZnSe.

Термический анализ был выполнен на дериватографе ОД-102 в стационарной воздушной среде, в открытых платиновых тиглях. Одновременно записывались кривые ДТА и ТГ. Максимальная температура нагрева составляла $1000{ }^{\circ} \mathrm{C}$.

Для оценки микрорельефа и элементного состава поверхности использовалась растровая электронная микроскопия (микроскоп JSM6400, Jeol) и рентгеноспектральный элементный анализ в энергодисперсионном режиме.

Исследования наноразмерной морфоструктуры внешней поверхности и продольных, а также поперечных сколов волокон керита проводились на атомно-силовом микроскопе Aris-3500 (применялись модули с максимальным полем сканирования $70 \times 70$ и $7 \times 7 \mu$ м) (Burleigh Instrument Co). В качестве зондов использовались стандартные кремниевые кантилеверы (Burleigh) пирамидальной формы с радиусом закругления кончика $\sim 10$ нм и жесткостью $0.1 \mathrm{H} /$ м. Все изображения поверхности были получены на воздухе при комнатной температуре. Съемки проводились как при постоянной высоте, так и при постоянной силе взаимодействия «зонд-образец» в контактном режиме (уровень сил $10^{-8}-10^{-9} \mathrm{H}$ ).

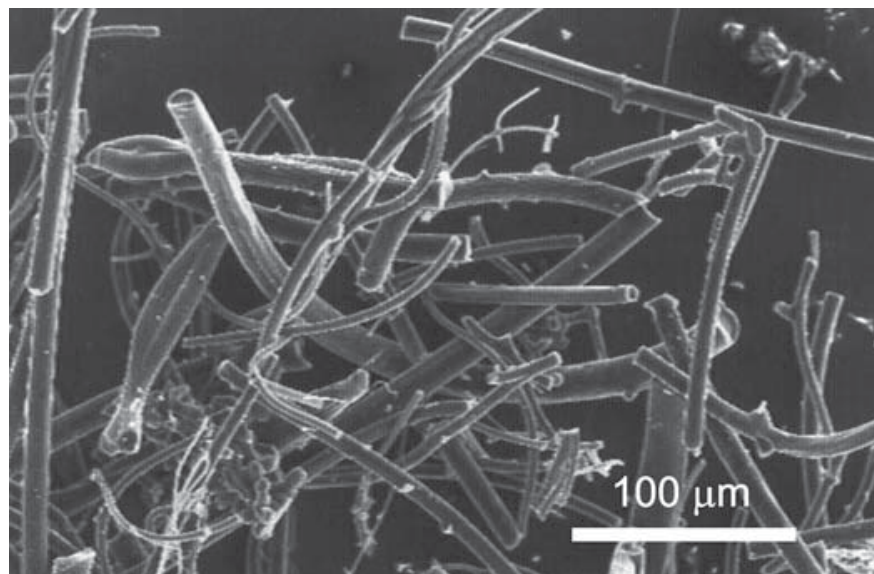

Рис. 1. Волокна волынского керита (РЭМ-изображение) Fig. 1. Fibers of Volyn kerite (SEM image)
Для съемки внешней поверхности керитовых волокон они наклеивались на подложку, в качестве которой использовались монокристаллические кремниевые пластинки, с помощью эпоксидной смолы. На приготовленных таким же способом образцах были получены продольные сколы волокон путем раскалывания закрепленного на подложке волокна с помощью остро заточенной вольфрамовой проволоки.

Для изучения морфологии поперечных сколов использовался следующий способ: войлокообразная масса керита, предварительно растертая и превращенная в порошок из одиночных волокон, была помещена в кювету и залита насыщенным раствором $\mathrm{NaCl}$. После нескольких суток хранения в комнатных условиях по мере испарения воды образовывались кубические кристаллы $\mathrm{NaCl}$ размерами до 0.5 см с включенными в них волокнами (до нескольких десятков). Эти кристаллы раскалывались, причем плоскость скола выбиралась под бинокуляром так, чтобы она пересекала скопление волокон, существенная часть которых располагалась поперек этой плоскости. В результате на атомарно-гладкой поверхности скола кристалла $\mathrm{NaCl}$ формировались поперечные сколовые поверхности волокон керита (рис. 2).

\section{Результаты и обсуждение}

В ИК-спектре волынского керита отчетливо выражены полосы поглощения, отвечающие валентным (2960-2910, $2880 \mathrm{~cm}^{-1}$ ) и деформационным (1460-1390, $880 \mathrm{~cm}^{-1}$ ) колебаниям $\mathrm{CH}_{3}, \mathrm{CH}_{2}$ и $\mathrm{CH}$ алифатических и нафтеновых групп. Кроме того, наблюдается ряд полос поглощения, обусловленных колебаниями различных кислородсодержащих групп. Полосы при 1700, $1610,1400-1470,1170-1040 \mathrm{~cm}^{-1}$ отражают молекулярные связи ароматических групп $\mathrm{C}=\mathrm{C}$, сопряженных с кислородом ( $\mathrm{C}-\mathrm{O}, \mathrm{C}-\mathrm{O}-\mathrm{C},-\mathrm{C}=\mathrm{O})$, а также $\mathrm{C}-\mathrm{C}$ групп. Полоса поглощения при $720 \mathrm{~cm}^{-1}$ обусловлена колебаниями длинных алифатических цепей $-\left(\mathrm{CH}_{2}\right)_{\mathrm{n}-}$, где $\mathrm{n} \geq 4$. Широкая полоса поглощения при $3400 \mathrm{~cm}^{-1}$ характеризует валентные колебания -OH-групп и $\mathrm{H}_{2} \mathrm{O}$. Полученные нами ИК-спектры в целом схожи с таковыми для волын-

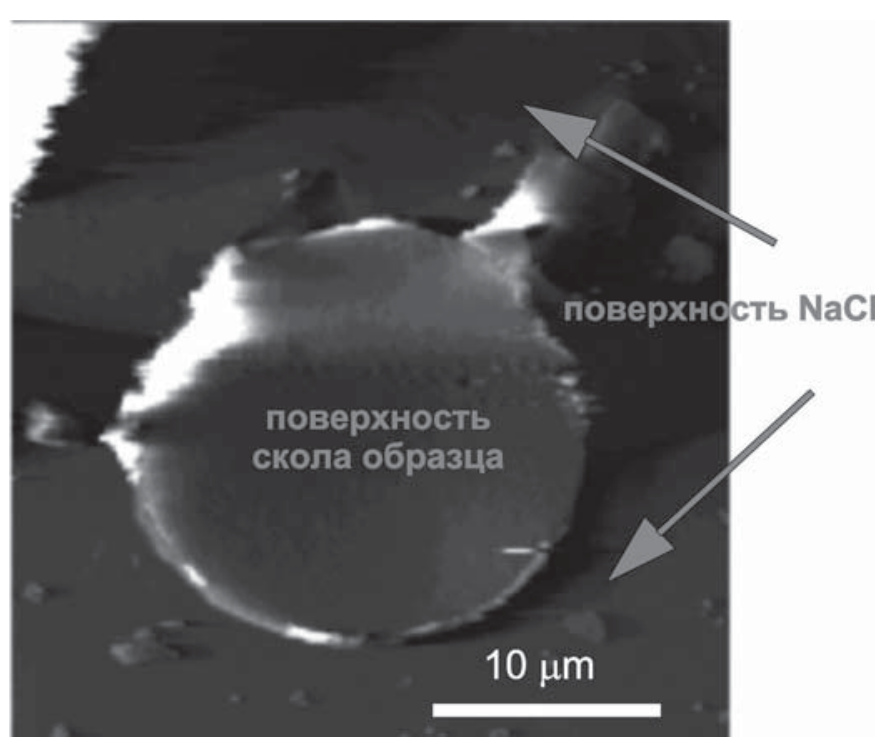

Рис. 2. Поперечный скол волокна волынского керита, помещенного в кристалл $\mathrm{NaCl}$

Fig. 2. Cross-cleavage of fiber of Volyn kerite placed in a $\mathrm{NaCl}$ crystal 
ского керита, приведенными ранее в работе [4], однако авторы указанной работы не определяли класс битума на основе полученных спектров. В целом результаты ИКспектроскопии свидетельствуют о том, что вещество относится к слабопреобразованным углеродистым веществам, соответствуя по своей химической структуре классу низших керитов [7].

ДТА волынского керита свидетельствует о двухэтапной термоокислительной деструкции. На первом этапе в интервале температур $20-160{ }^{\circ} \mathrm{C}$ происходит испарение адсорбированной воды, потеря массы образца незначительна и составляет $5.3 \%$, при этом записывается небольшой эндоэффект с минимумом при $120{ }^{\circ} \mathrm{C}$. Второй этап термоокислительной деструкции начинается при температуре $270{ }^{\circ} \mathrm{C}$ и заканчивается при $570{ }^{\circ} \mathrm{C}$. На кривой ДТА этот процесс записывается одним экзотермическим эффектом с максимумом при $480{ }^{\circ} \mathrm{C}$ и наблюдается максимальная потеря массы образца (90.6 \%). Характер термоокислительной деструкции, как и представленные выше данные ИК-спектров, схож с таковой для низших керитов.

Атомно-силовая микроскопия (АСМ), так же как и ранее электронная [11], не выявляет каких-либо наноразмерных морфологических особенностей на гладкой поверхности волокон керита (рис. 3). Спорадически встречаются отмеченные в работах $[11,17]$ микродефекты в виде пор и одиночных холмов (бугорков).

Полученные методом АСМ изображения поверхности поперечных и продольных сколов волокон позволяют визуализировать рельеф, соответствующий смешанной глобулярно-волокнистой субмикроструктуре (рис. 4), с преобладанием нановолокон (этот термин вводится нами здесь для различения элементов надмолекулярной структуры и собственно индивидов волокнистого керита). Размер поперечного сечения нановолокон переменчив, иногда наблюдаются каплевидные утолщения, рас-

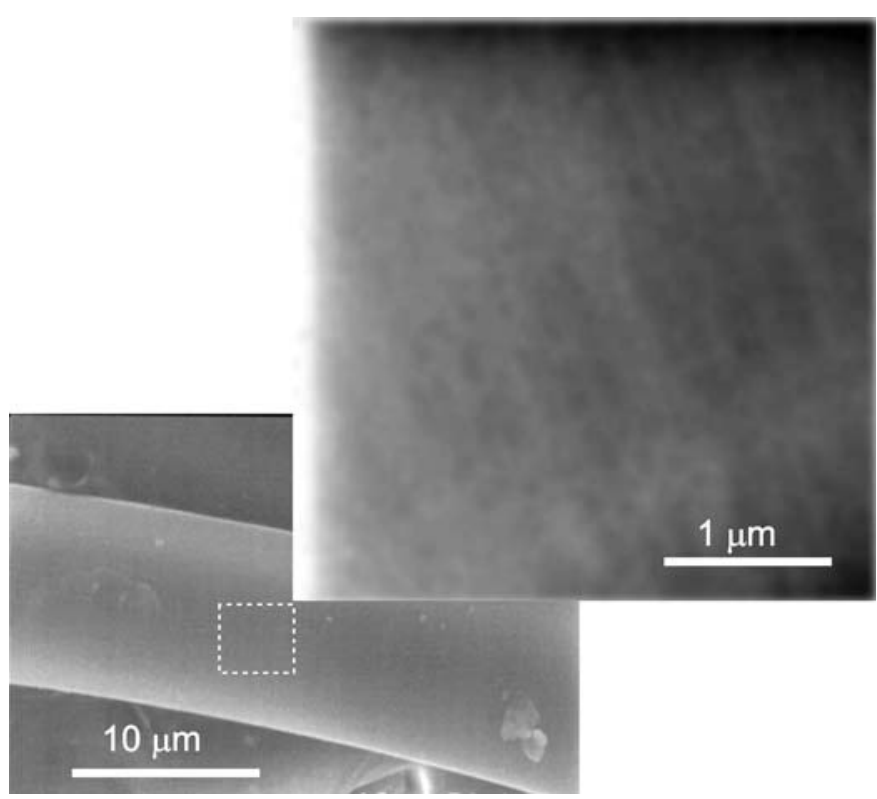

Рис. 3. Внешняя поверхность волокна волынского керита: а) РЭМ-изображение (общий вид); б). АСМ-изображение (увеличенный фрагмент на РЭМ-изображении выделен квадратным контуром)

Fig. 3. The external surface of fiber of Volyn kerite: a) SEM image (general view); b) AFM image (enlarged fragment on the SEM image is highlighted square contour) полагающиеся, как правило, симметрично относительно их оси. Ряд нановолокон имеют вид скрученных жгутов. Некоторые изгибы нановолокон имеют довольно резкие изломы, что косвенно может свидетельствовать о наличии в них полостей, т. к. подобное явление характерно для любых физических тел трубчатого строения. Нередко нановолокна разветвлены. Их видимый диаметр изменяется в диапазоне от 50 до 100 нм, в среднем он составляет около 80 нм. Такой диаметр элементов надмолекулярной структуры характерен и для волокон керита диаметром несколько микрометров, и для волокон, диаметр которых составляет несколько десятков микрометров. Упаковка нановолокон очень плотная. Отметим, что у части исследованных образцов локальное среднестатистическое направление ориентации нановолокон сохраняется по всей поверхности поперечного скола волокна. Предполагая, что мы наблюдаем явление складывания (переламывания) нановолокон, обусловленное их гибкостью [3], часть наблюдаемых на поперечных сколах вытянутых элементов морфоструктуры можно интерпретировать как выходы оборванных нановолокон либо фрагменты их изгибов (рис. 5). Такая интерпретация соответствует картине преимущественно нановолокнистого строения, выявляемой на продольных сколах волокон волынского керита (рис. 6). Хотя в плоскости изображения микроскопа направления ориентации отдельных нановолокон меняются в незначительных пределах, статистически они ориентированы преимущественно в одном направлении. Об этом свидетельствует характерный асимметричный вид фурье-образов изображений надмолекулярной структуры волокнистого керита (рис. 6). Он соответствует морфологическим картинам с неупорядоченным расположением формирующих фурье-образ элементов, которые, тем не менее имеют выделенное направление ориентации [9].

Наблюдаемые на поверхности сколов шаровидные и эллипсоидальные образования, по нашему мнению, представляют собой глобулярную составляющую надмолекулярной структуры волокнистого керита. Разнообразие форм эти образования приобрели, вероятно, находясь в эластичном состоянии, вследствие контактного взаимодействия друг с другом в стесненных условиях в процессе макромолекулярного структурирования вещества волокон. Чаще всего наблюдаются изогнутые гантелеобразные, вытянутые глобулярные, каплевидные формы (рис. 4, 5). Их максимальные видимые размеры колеблются от десятков до сотен нанометров. При этом с учетом наблюдения преимущественно волокнистого строения на продольном сколе часть глобулярных элементов также можно рассматривать как оборванные фрагменты волокон.

Для описания стадии структурного состояния природных углеродистых веществ многими исследователями $[8,13]$ используется сопоставление их надмолекулярных структур с таковыми искусственных полимеров. Как описывается в работах $[12,15]$, надмолекулярное структурирование, подобное наблюдаемому в волынском керите, в полимерах является следствием существования локальных областей, отличающихся высокой степенью внутренней упорядоченности атомно-молекулярной структуры. В этих областях полимерные цепные молекулы расположены строго ориентированно друг относительно друга и в процессе ассоциирования создают наблюдаемые нами более крупные структурные образова- 

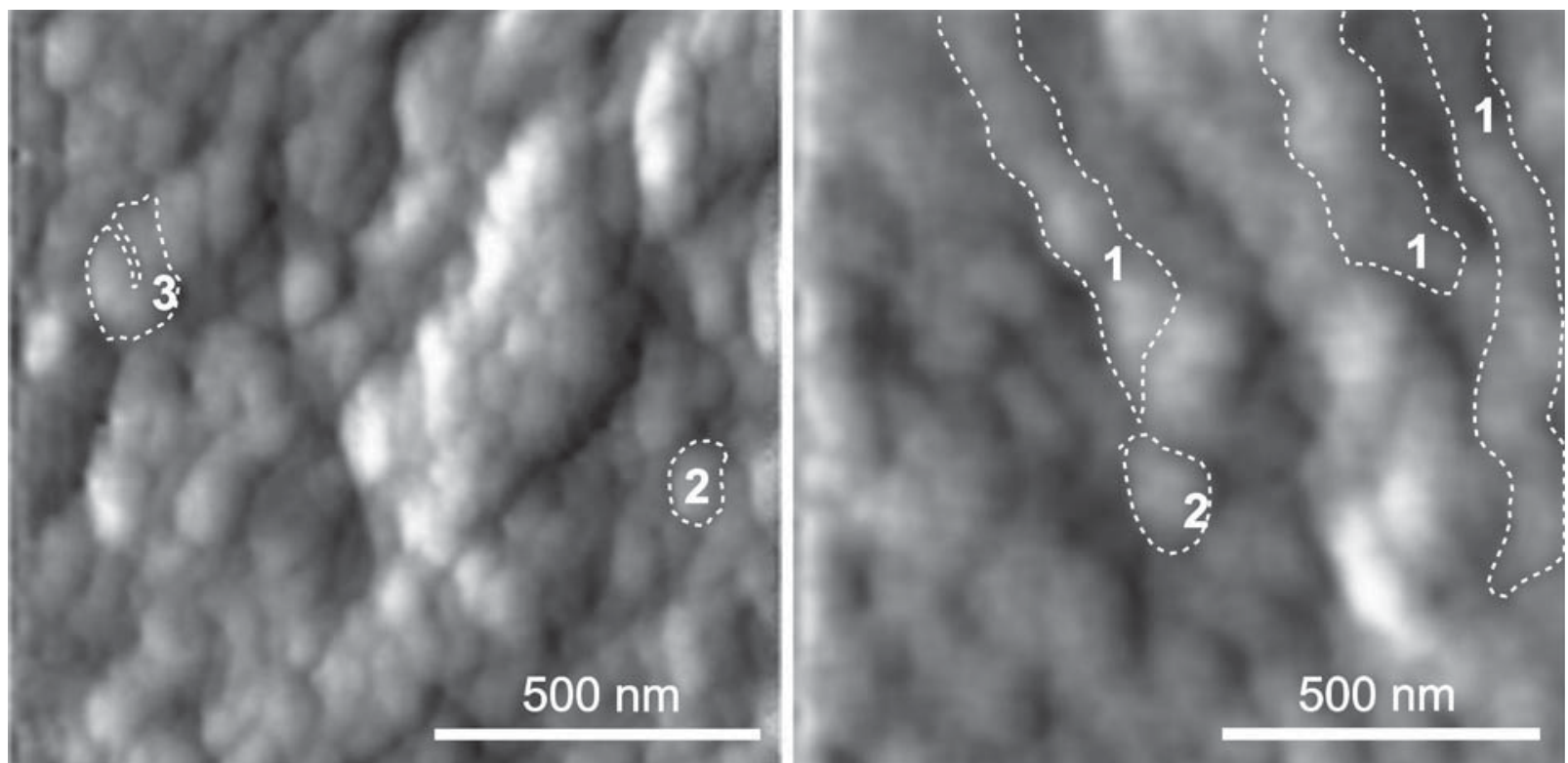

Рис. 4. Волокнисто-глобулярная надмолекулярная структура волынского керита (поперечный скол, АСМ-изображения): 1 нановолокна; 2 - глобулы; 3 - излом элемента надмолекулярной структуры

Fig. 4. The fiber-globular supermolecular structure of Volyn kerite (cross-cleavage, the AFM image): 1 - nanofibers; 2 - globules; 3 - a kink of element of supermolecular structure

ния - нановолокна и глобулы. Вероятно, о подобных упорядоченных молекулярных кластерах размерами до 5 нм написано в работах Н. П. Юшкина по результатам высокоразрешающей просвечивающей электронной микроскопии $[16,17]$. Обнаруженная им наноразмерная пористость с размерами пор 10-20 нм также состыкуется с нашим предположением о трубчатом строении части нановолокон диаметром 50-100 нм. Сравнение надмолекулярного строения волынского керита с таковым для природных твердых битумов разных классов [13] показывает, что у волынского керита присутствует характерная для керитов глобулярно-волокнистая надмолекуляр- ная структура, а преобладание волокнистой составляющей свидетельствует о том, что степень преобразования углеводородного вешества этого керита ближе к стадии низших керитов, что подтверждается результатами ИКспектроскопии и ДТА.

Совершенство морфологии внешней поверхности волокон керита, проявляющееся в отсутствии нанометрического рельефа, с учетом наличия субмикронного внутреннего структурирования, может являться следствием перестройки поверхностных макромолекул в условиях их достаточно высокой подвижности (обусловленной, вероятно, температурным фактором) под действи-

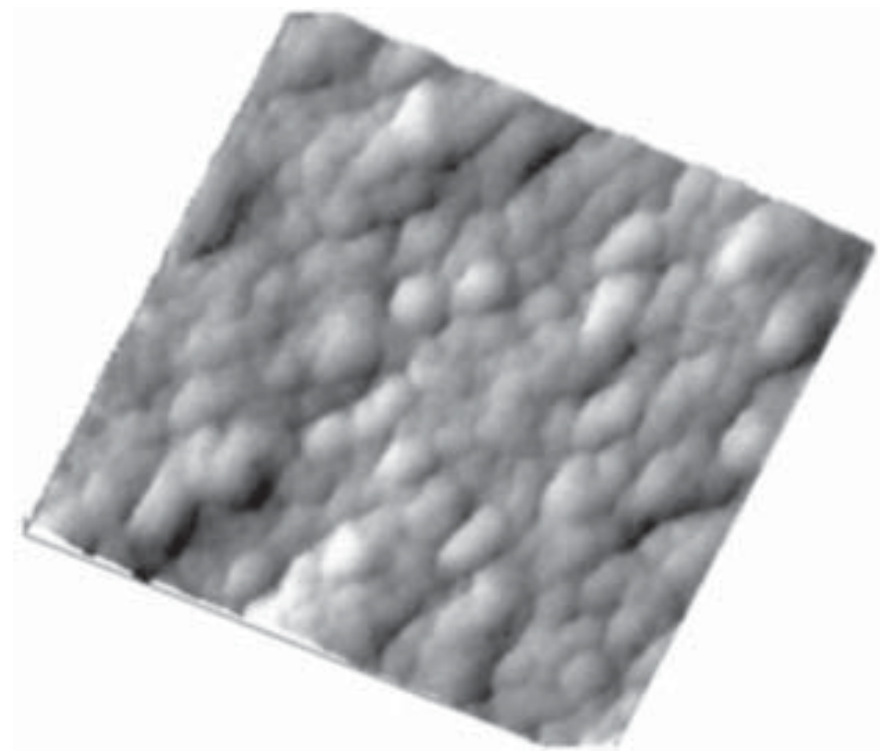

Рис. 5. Участок поверхности с относительно высоким содержанием глобулярной составляющей надмолекулярной структуры (поперечный скол, АСМ-изображение, размер скана $1.4 \times 1.4 \mu \mathrm{m})$

Fig. 5. The surface region with relatively high content of the globular component of supermolecular structure (cross-cleavage, AFM-image, scan size $1.4 \times 1.4 \mu \mathrm{m}$ )

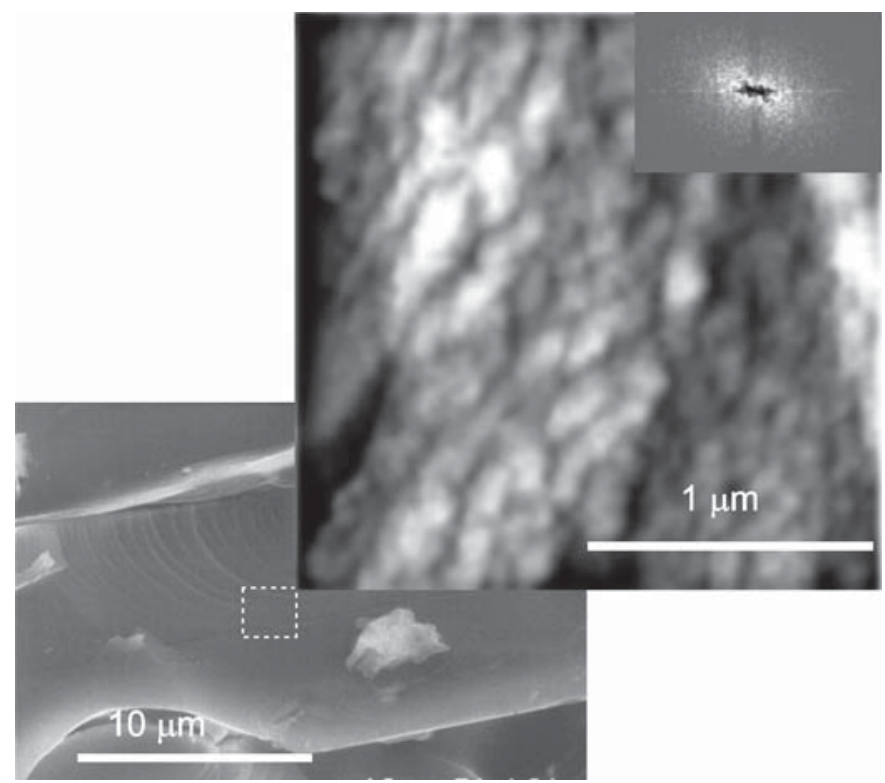

Рис. 6. Продольный скол волокна керита: а) РЭМ-изображение; б) АСМ-изображение (увеличенный фрагмент на РЭМ-изображении указан квадратом). На врезке - фурьеобраз АСМ-изображения

Fig. 6. Longitudinal cleavage of fiber: a) SEM image; b) AFM image (enlarged fragment on the SEM image indicated square contour). The inset shows a Fourier transform of the AFM image 
ем сил поверхностного натяжения. Эти силы приводили структуру поверхности в состояние, соответствующее минимуму свободной энергии, формируя своеобразную поверхностно-упорядоченную на молекулярном уровне фазу.

После нагрева образца волынского керита при 500 ${ }^{\circ} \mathrm{C}$ в течение 10 часов на ДТА-кривой происходит увеличение температуры основных эндо- и экзоэффектов, которые составляют 180 и $500{ }^{\circ} \mathrm{C}$ соответственно. При этом начало и окончание термоокислительной деструкции смещается также в сторону увеличения температур и составляет 340 и $615{ }^{\circ} \mathrm{C}$ соответственно. Характер термоокислительной деструкции становится схож с таковой для высших керитов.

Можно предположить, что в области 480-500 ${ }^{\circ} \mathrm{C}$ происходит окисление образца, при котором происходит реакция разложения нафтеновой и алифатической части молекулярной структуры оксикерита. Разложение нафтеновых углеводородов происходит вследствие диспропорционирования водорода, в результате чего образуются низкомолекулярные углеводороды, преимущественно метанового ряда, и высокомолекулярные углеводороды ароматического типа, о чем свидетельствуют данные пиролитической газовой хроматографии. Кроме того, имеет место распад кислородных и эфирных мостиковых связей, о чем свидетельствуют данные ИКспектроскопии. На ИК-спектре прогретого керита наблюдается уменьшение интенсивности алифатических и нафтеновых групп, а также кислородсодержащих (карбоксильных, карбонильных, фенольных, гидроксильных групп и $\mathrm{C}=\mathrm{O}$ альдегидов и кетонов). Отсутствует полоса поглощения длинных парафиновых цепей. При этом увеличивается интенсивность поглощения поликонденсированных ароматических связей. Таким образом, только после прогрева при $500{ }^{\circ} \mathrm{C}$ степень преобразованности данного вещества достигает стадии высшего керита [7].

\section{Заключение}

С помощью атомно-силовой микроскопии установлено, что структура волокнистого керита на субмикронном уровне образована преимущественно нановолокнами диаметром 50-100 нм, нередко имеющими трубчатое строение, и в меньшей степени вытянутыми глобулами. Глобулы, как правило, агрегируются в цепочки, что может свидетельствовать как о том, что вещество находится на завершающей структурной стадии перехода глобулярной структуры в линейную (нановолокнистую), так и о параллельном формировании глобул и нановолокон с преобладанием нановолокон. Во взаимном расположении нановолокон отмечается наличие статистически выделенных направлений, при этом ориентация сохраняется вдоль большей части поверхности как поперечного, так и продольного скола. Вероятно, нановолокна и сонаправленные им глобулярные цепочки формировали в процессе роста собственно волокна керита, в связи с чем элементы надмолекулярной структуры имеют преимущественное направление ориентации в соответствии с направлением роста керитового волокна. Сравнение соотношения глобулярно-волокнистых форм надмолекулярных структурных элементов и данные ИКспектроскопии указывают на то, что волынский керит по степени своей преобразованности больше соответствует слабопреобразованным разностям твердых битумов, а именно низшим керитам.
Выражаем благодарность А.В. Андрееву за проведение ИК-спектроскопических исследований и В.Н. Филиппову за электронно-микроскопический анализ. Исследования проводились при частичной финансовой поддержке проекта УрО РАН (№ 15-18-5-45).

\section{Литература}

1. Гинзбург А. И., Булгаков В. С., Василишин К. С., Лукьянова В. Т., Солнцева Л. С., Урманова А. М., Успенский В. А. Керит из пегматитов Волыни // Докл. АН СССР. 1987. Т. 292. № 1. C. $188-191$.

2. Королев Ю. М. Рентгенографическая характеристика нафтидов // Литология и полезные ископаемые. 1998. № 6. C. 647-659.

3. Коршак В. В. Химия высокомолекулярных соединений. М.: Наука, 1950. 499 с.

4. Лобзова Р. В., Лукьянова В. Т., Звягин Б. Б., Зиборова Т. А., Жухлистов А. П., Трубкин Н. В. Волокнистый керит из пегматитов Волыни // Конденсированное некристаллическое состояние вещества земной коры. СПб.: Наука, 1995. С. 100104.

5. Лукьянова В. Т., Королев Ю. М., Попов В. Т., Сынгаевский E. Д., Урманова А. М. Новые данные о волокнистом керите из пегматитов Волыни // Труды Минералогич. музея АН СССР. 1989. В. 38. C. 87-95.

6. Малеев М. Н. Свойства и генезис природных нитевидных кристаллов и их агрегатов. М.: Наука, 1971. 200 с.

7. Мартиросян O. В. Факторы и механизмы структурной эволюции органических минералов и минералоидов. Изд-во Екатеринбург: УрО РАН, 2012. 241 с.

8. Пеньков В. Ф. Генетическая минералогия углеродистых веществ. М.: Недра, 1996. 224 с.

9. Чалых А. Е., Загайтов А. И., Чертков В. Г., Макаров Г. Н. Применение фурье-преобразования для анализа морфологических картин фазового распада в полимерных системах // Высокомолекулярные соединения. Б. 2000. Т. 42. № 12. C. 2197-2204.

10. Юшкин Н. П., Павлишин В. И. Морфология и онтогенез волокнистого керита из пегматитов Волыни // Конденсированное некристаллическое состояние вещества земной коры. Сыктывкар, 1989. С. 42-43.

11. Юшкин Н. П. Фибраляция твердых углеводородов // Известия АН СССР. Серия геологическая. 1990. № 10. C. $102-111$.

12. Юшкин Н. П. Кривогранные кристаллы // Теоретическая, минералогическая и техническая кристаллография, Сыктывкар: Геопринт, 1998. С. 58-59.

13. Golubev Ye. A., Kovaleva O. V., Yushkin N. P. Observations and morphological analysis of supermolecular structure of natural bitumens by atomic force microscopy // Fuel, 2008. V. 87. N. 1. P. 32-38.

14. Gorlenko V. M., Zhmur S. I., Duda V. I., Osipov G. A., Suzina N., Dmitriev $V . V$. Microbial nature of fibrous kerite of Volyn / Proc. SPIE, Instruments, Methods, and Missions for Astrobiology II. 1999. P. 83-94.

15. Kawaguchi M., Nozaki K., Motojima S., Iwanaga $H$. A growth mechanism of regularly coiled carbon fibers through acetylene pyrolysis. // J. of Crystal Growth. 1992. V. 118. P. 309313.

16. Yushkin N. P. Natural polymer crystals of hydrocarbons as models of prebiological organisms // Journal of Crystal Growth. 1996. V. 167. P. 237-247.

17. Yushkin N. P. Hydrocarbons crystals as protoorganisms and biological systems predessors. // Part of SPIE Conference on 
Instruments, Methods and Missions for Astrobiology. San Diego. 1999. P. 234-244.

\section{References}

1. Ginzburg A. I., Bulgakov B. C., Vasilishin K. S., Lukyanova V. T., Solntseva L. S., Urmanova A. M., Uspenskii V. A. Kerit iz pegmatitov Volyni (Kerite from Volyn pegmatites). Dokl. AN SSSR. 1987, V. 292, No. 1, pp. 188-191.

2. Korolev $Y$ u. M. Rentgenograficheskaya harakteristika naftidov (X-ray characteristics of naphtides). Litologiya i poleznye iskopaemye. 1998, No. 6, pp. 647-659.

3. Korshak $V$. V. Himiya vysokomolekulyarnyh soedinenii (Chemistry of high molecular compound). Moscow, Nauka, 1950, 499 pp.

4. Lobzova R. V., Lukyanova V. T., Zvyagin B. B., Ziborova T. A., Zhuhlistov A. P., Trubkin N. V. Voloknistyi kerit iz pegmatitov Volyni (Fibrous kerite from Volyn pegmatites). Kondensirovannoe nekristallicheskoe sostoyanie veschestva zemnoi kory. St. Petersburg, Nauka, 1995, pp. 100-104.

5. Lukyanova V. T., Korolev Yu. M., Popov V. T., Syngaevskii E. D., Urmanova A. M. Novye dannye o voloknistom kerite iz pegmatitov Volyni (New data about fibrous kerite from Volyn pegmatites). Trudy Mineralogich. Muzeya AN SSSR. 1989, V. 38, pp. 87-95.

6. Maleev M. N. Svoistva i genezis prirodnyh nitevidnyh kristallov $i$ ih agregatov (Features and genesis of natural filamentary crystals). Moscow, Nauka, 1971, 200 pp.

7. Martirosyan $O$. $V$. Faktory i mehanizmy strukturnoi evolyutsii organicheskih mineralov i mineraloidov (Factors and mechanisms of structural evolution of organic minerals and mineraloids). Ekaterinburg, UB RAS, 2012, 241 pp.

8. Penkov V. F. Geneticheskaya mineralogiya uglerodistyh veschestv (Genetic mineralogy of carboniferous substances). Moscow, Nedra, 1996, 224 pp.
9. Chalyh A. E., Zagaitov A. I., Chertkov V. G., Makarov G. $N$. Primenenie Fure-preobrazovaniya dlya analiza morfologicheskih kartin fazovogo raspada $\mathrm{v}$ polimernyh sistemah (Fourier transformation for analysis of morphological patterns of phase decomposition in polymer systems). Vysokomolekulyarnye soedineniya, 2000, V. 42, No. 12, pp. 2197-2204.

10. Yushkin N. P., Pavlishin V. I. Morfologiya i ontogenez voloknistogo kerita iz pegmatitov Volyni (Morphology and ontogenesis of fibrous kerite from Volyn pegmatites). Kondensirovannoe nekristallicheskoe sostoyanie veschestva zemnoi kory. Syktyvkar, 1989, pp. 42-43.

11. Yushkin N. P. Fibralyatsiya tverdyh uglevodorodov (Fibrolation of solid hydrocarbons). Izvestiya AN SSSR. Seriya geologicheskaya. 1990, No. 10, pp. 102-111.

12. Yushkin N. P. Krivogrannye kristally (Curve-faced crystals). Teoreticheskaya, mineralogicheskaya i tehnicheskaya kristallografiya, Syktyvkar, Geoprint, 1998, pp. 58-59.

13. Golubev Ye. A., Kovaleva O. V., Yushkin N. P. Observations and morphological analysis of supermolecular structure of natural bitumens by atomic force microscopy. Fuel, 2008, V. 87, No. 1, pp. 32-38.

14. Gorlenko V. M., Zhmur S. I., Duda V. I., Osipov G. A., Suzina N., Dmitriev V. $V$. Microbial nature of fibrous kerite of Volyn. Proc. SPIE, Instruments, Methods, and Missions for Astrobiology II, 1999, pp. 83-94.

15. Kawaguchi M., Nozaki K., Motojima S., Iwanaga $H$. A growth mechanism of regularly coiled carbon fibers through acetylene pyrolysis. J. of Crystal Growth. 1992, V. 118, pp. 309-313.

16. Yushkin N. P. Natural polymer crystals of hydrocarbons as models of prebiological organisms. Journal of Crystal Growth, 1996, V. 167, pp. 237-247.

17. Yushkin N. P. Hydrocarbons crystals as protoorganisms and biological systems predessors. Part of SPIE Conference on Instruments, Methods and Missions for Astrobiology. San Diego, 1999, pp. 234-244. 